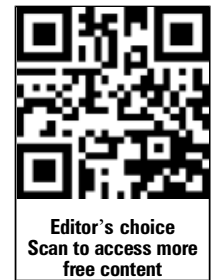

free content
${ }^{1}$ Heart Research Centre,

Melbourne, Australia

${ }^{2}$ School of Nursing and

Midwifery, Monash University,

Melbourne, Victoria, Australia

${ }^{3}$ Department of Psychiatry,

University of Melbourne,

Melbourne, Victoria, Australia

${ }^{4}$ Faculty of Medicine, University of Melbourne, Melbourne,

Victoria, Australia

${ }^{5}$ Department of Cardiothoracic

Surgery, Royal Melbourne

Hospital, University of

Melbourne, Melbourne,

Victoria, Australia

${ }^{6}$ Department of Medicine,

Royal Melbourne Hospital,

University of Melbourne,

Melbourne, Victoria, Australia

\section{Correspondence to}

Dr Alison Beauchamp, Heart

Research Centre, Royal

Melbourne Hospital, PO Box

2137, Post Office, Melbourne

VIC 3050, Australia; alison.

beauchamp@

heartresearchcentre.org

Received 16 September 2012 Revised 31 October 2012

Accepted 6 November 2012

Published Online First

4 December 2012

\section{SLinked}

- http://dx.doi.org/10.1136/ heartjnl-2012-303365

To cite: Beauchamp $A$ Worcester $\mathrm{M}, \mathrm{Ng} \mathrm{A}$, et al. Heart 2013;99:620-625.

\title{
Attendance at cardiac rehabilitation is associated with lower all-cause mortality after 14 years of follow-up
}

\author{
Alison Beauchamp ${ }^{1,2}$ Marian Worcester, ${ }^{1,3}$ Andrew $\mathrm{Ng}_{1}{ }^{1,4}$ Barbara Murphy, ${ }^{1,3}$ \\ James Tatoulis, ${ }^{5}$ Leeanne Grigg, ${ }^{6}$ Robert Newman, ${ }^{6}$ Alan Goble ${ }^{1}$
}

\begin{abstract}
Objective To investigate whether attendance at cardiac rehabilitation (CR) independently predicts all-cause mortality over 14 years and whether there is a doseresponse relationship between the proportion of $C R$ sessions attended and long-term mortality.

Design Retrospective cohort study.

Setting CR programmes in Victoria, Australia

Patients The sample comprised 544 men and women eligible for CR following myocardial infarction, coronary artery bypass surgery or percutaneous interventions. Participants were tracked 4 months after hospital discharge to ascertain CR attendance status.

Main outcome measures All-cause mortality at 14 years ascertained through linkage to the Australian National Death Index.
\end{abstract}

Results In total, 281 (52\%) men and women attended at least one $C R$ session. There were few significant differences between non-attenders and attenders. After adjustment for age, sex, diagnosis, employment, diabetes and family history, the mortality risk for nonattenders was $58 \%$ greater than for attenders $(H R=1.58,95 \% \mathrm{Cl} 1.16$ to 2.15). Participants who attended $<25 \%$ of sessions had a mortality risk more than twice that of participants attending $\geq 75 \%$ of sessions ( $\mathrm{OR}=2.57,95 \% \mathrm{Cl} 1.04$ to 6.38$)$. This association was attenuated after adjusting for current smoking (OR=2.06, $95 \% \mathrm{Cl} 0.80$ to 5.29 ).

Conclusions This study provides further evidence for the long-term benefits of $C R$ in a contemporary, heterogeneous population. While a dose-response relationship may exist between the number of sessions attended and long-term mortality, this relationship does not occur independently of smoking differences. $C R$ practitioners should encourage smokers to attend $C R$ and provide support for smoking cessation.

\section{BACKGROUND}

Coronary heart disease (CHD) remains the leading cause of death globally and it is essential that interventions shown to be effective in slowing progression of the disease are used where appropriate. Cardiac rehabilitation (CR) is one such intervention, with attendance at CR shown in many studies to be strongly associated with a reduction in allcause mortality. ${ }^{1-8}$ However, few studies have investigated the longer-term benefits of $\mathrm{CR}$ and findings are mixed. ${ }^{9-11}$ One study from the USA found no difference in mortality at 19 years, ${ }^{10}$ while in Sweden, attendance at CR was associated with a reduction in mortality after 10 years, but not after 5 years. ${ }^{9}$ Further investigation of the longterm benefits of CR may provide valuable evidence to support the use of this intervention in slowing the progression of CHD. Moreover, most earlier studies reporting outcomes after CR included only younger male patients after acute myocardial infarction (AMI). No identified contemporary study has investigated the long-term effects of CR on mortality among the spectrum of patients most commonly referred to CR programmes today. These include older patients, women or other diagnostic groups, such as those who have undergone coronary artery bypass graft (CABG) surgery or percutaneous interventions (PCIs).

Adherence to $\mathrm{CR}$ programmes may also influence the survival benefits associated with CR. It is unclear whether there is a dose-response relationship between the proportion of $\mathrm{CR}$ sessions attended and all-cause mortality, particularly over the longer term. ${ }^{2}{ }^{78}$ Evidence for such a relationship will support the development of strategies to encourage patients to remain in CR programmes. This study aims to investigate whether attendance at a CR programme independently predicts allcause mortality over 14 years in 544 Australian men and women after AMI, CABG surgery or PCI, and whether there is a dose-response relationship between the proportion of CR programme sessions attended and long-term mortality.

\section{METHODS}

\section{Study population}

The sample for this study was drawn from 652 participants recruited for an earlier study investigating attendance patterns after referral to CR. Details and results of the study have been reported elsewhere. ${ }^{12}$ Subjects for the original attendance patterns study were patients with AMI, CABG or PCI who were consecutively admitted over an 11-month period during 1996 and 1997 to one of two major teaching hospitals in Melbourne. In accordance with the prevailing policy in Victoria of automatic referral to $\mathrm{CR}$, all patients were encouraged to attend a CR programme at these and other hospitals in Victoria. Participants were tracked for 4 months after their acute event to determine their CR attendance. This subsequent follow-up study uses a retrospective cohort design to examine longterm mortality outcomes of the participants enrolled in the original attendance patterns study- 
that is, the 573 patients whose CR attendance was successfully determined. To allow for disease severity and avoid survival bias, we excluded 12 participants who died within 1 year of their cardiac event. ${ }^{5} 13$ A further 17 had inadequate CR attendance records, leaving 544 subjects $(83.4 \%$ of the 652 patients in the original attendance patterns study) available for this follow-up mortality study.

\section{Description of CR programmes}

Consistent with the usual model of CR programme delivery in Australia at that time, the outpatient CR programmes $(n=43)$ attended by study participants consisted of $1 \mathrm{~h}$ of low-to-moderate-intensity exercise and $1 \mathrm{~h}$ of education per session, delivered by a multidisciplinary team of health professionals. Education topics included CHD, risk factor modification, psychosocial issues and return to usual activities. Programmes were group-based, but individual counselling was available if required. The programme duration was between six and 12 sessions, with most being between six and eight sessions. ${ }^{14}$ For this study, CR 'attenders' were defined as attending at least one session of group-based exercise and education. 'Non-attenders' at CR were those patients who attended no sessions. These definitions are consistent with those used in previous studies. ${ }^{1} 15$

The original attendance patterns study (1996-7) was approved by the human research ethics committees of both hospitals. All subjects provided written informed consent for a brief baseline interview, access to hospital medical records and further contact. Ethics approval for this follow-up mortality study was received from the Australian Institute of Health and Welfare and the human research ethics committee representing both hospitals.

\section{Baseline risk factors}

Baseline interviews were conducted with patients to investigate sociodemographic, medical and behavioural characteristics. Sociodemographic factors included age, gender, marital status (married or de facto vs separated, divorced, widowed or never married) and living arrangements (living alone vs living with partner, relatives, friends or in a hostel). Questions were also asked about country of birth (Australia vs other), language spoken at home (English vs other language) and adequacy of spoken English (poor vs satisfactory), age of leaving school, occupation when in the workforce (non-manual vs manual according to the Australian Standard Classification of Occupations) $^{16}$ and employment status (employed vs unemployed, retired, pensioner or home duties).

Medical variables included diagnosis (AMI, CABG or PCI), family history of heart disease (parent or sibling died of heart disease before age 65 years) and self-reported high blood pressure, high cholesterol or diabetes. Participants also reported their weight and height.

Behavioural characteristics included smoking status (currently smokes an occasional cigarette or more vs not currently smoking) and physical activity in the 3 months before admission $(>6 \mathrm{~h}$ leisure-time activity per week vs $<6 \mathrm{~h}$ ). Assessment of behavioural, medical and sociodemographic factors was based on self-report using questions and protocols taken from previous national surveys of the prevalence of cardiovascular disease risk factors. ${ }^{12} 17$

\section{Ascertainment of mortality}

Participant mortality was ascertained by linking to the Australian National Death Index (NDI), the national dataset of all deaths occurring in Australia since 1980. The NDI has been shown previously to have a sensitivity of $93.7 \%$ and specificity of $100 \%$ for the identification of deaths. ${ }^{18}$ The full name, date of birth and date of last known contact of study subjects were submitted to the NDI for automated record linkage. Results were also manually reviewed against our records to confirm matching.

\section{Statistical analysis}

Analyses were performed using Stata 10.1 (Stata Corp, College Station, Texas, USA). Baseline risk factors and sociodemographic data are reported as means or proportions. To identify covariates to be controlled for in predictive analyses, we assessed the significance of any difference in baseline variables between attenders and non-attenders using $\chi^{2}$ (for binary variables) and $t$ tests (for continuous variables). Survival was described using crude death rates. Cox proportional hazards models were constructed and HR and their 95\% CIs were calculated to assess the association between CR attendance (vs non-attendance) and all-cause mortality. For these analyses, time at risk began at an event date and ended at the date of death, or 17 December 2010, whichever came first. This model was extended to adjust for age and sex, with the subsequent model adjusting for significant baseline risk factors. The proportional hazards assumption was tested and met for all variables used in analysis.

For attenders, a variable 'proportion of CR sessions attended' was derived from the number of sessions actually attended by the participant, divided by the number of sessions available for that CR programme. This variable did not follow a normal distribution and was therefore modelled in four categories, based on attendance as follows: (1)10-24.9\%; (2) $25-49.9 \%$; (3) 50 $74.9 \%$ and (4) $75-100 \%$ of sessions. Two-sided $\mathrm{p}$ values are presented, with $\mathrm{p}$ values $<0.05$ regarded as significant.

\section{RESULTS}

\section{Non-attendance at CR}

Baseline characteristics of attenders and non-attenders

Relevant baseline characteristics are presented in table 1 . A total of $281(52 \%)$ men and women attended at least one exercise session. Few statistically significant differences were seen between attenders and non-attenders. Compared with those who did not attend any sessions, attenders were more likely to be male $(p=0.044)$, younger $(p=0.001)$ and to have undergone CABG $(p<0.001)$. Attenders were also more likely to be employed $(p=0.019)$ and to have a family history of heart disease $(p=0.008)$ and less likely to report having diabetes than non-attenders $(\mathrm{p}=0.012)$.

We also examined the characteristics of excluded participants. The 17 patients with inadequate CR records were more likely to have had an AMI $(p=0.007)$, while the 12 participants who died within 12 months of their event were more likely to have had an AMI $(p=0.048)$, not be employed $(p=0.020)$, live alone $(p=0.009)$, have left school earlier $(p=0.015)$ and have diabetes $(\mathrm{p}=0.027)$.

\section{Crude all-cause mortality rates and attendance at CR}

There were 199 deaths during a median follow up time of 14.2 years (interquartile range 9.7-14.5). Crude (unadjusted) all-cause mortality rates of attenders and non-attenders are shown in table 2. Among the total study population, nonattenders had a mortality rate per 10000 person years which was nearly double that of attenders. A similar trend was seen for both men and women, for those aged over 60 years at study baseline and for patients with AMI or CABG. 
Table 1 Baseline characteristics of cardiac rehabilitation attenders and non-attenders $(n=544)$

\begin{tabular}{|c|c|c|c|}
\hline Characteristics & $\begin{array}{l}\text { Attenders } \\
(n=281) \dagger\end{array}$ & $\begin{array}{l}\text { Non-attenders } \\
(n=263) \ddagger\end{array}$ & $\begin{array}{l}p \\
\text { Value* }\end{array}$ \\
\hline Male & $216(77)$ & $182(69)$ & 0.044 \\
\hline Age (years) mean, SD & $60.9 \pm 10.1$ & $64.2 \pm 12.3$ & 0.001 \\
\hline$\leq 49$ & $48(17)$ & $35(13)$ & 0.221 \\
\hline $50-59$ & $70(25)$ & $59(22)$ & 0.497 \\
\hline $60-69$ & $106(38)$ & $64(24)$ & 0.001 \\
\hline$\geq 70$ & $57(20)$ & $105(40)$ & $<0.001$ \\
\hline CABG & $104(37)$ & $51(19)$ & $<0.001$ \\
\hline AMI & $154(55)$ & $143(54)$ & 0.920 \\
\hline $\mathrm{PCl}$ & $23(8)$ & $69(26)$ & $<0.001$ \\
\hline Australian born & $129(46)$ & $133(51)$ & 0.277 \\
\hline Married & $214(76)$ & $181(69)$ & 0.055 \\
\hline Lives alone $(n=543)$ & $34(12)$ & $44(17)$ & 0.119 \\
\hline Speaks English at home $(n=540)$ & $193(69)$ & $183(70)$ & 0.915 \\
\hline Proficient English speaker $(n=540)$ & $253(91)$ & $233(89)$ & 0.422 \\
\hline Age left school $(n=519)$, mean, SD & $14.6 \pm 2.3$ & $14.7 \pm 2.0$ & 0.781 \\
\hline Manual occupation $(n=510)$ & $205(76)$ & $172(71)$ & 0.164 \\
\hline Currently employed & $101(36)$ & $70(27)$ & 0.019 \\
\hline Family history of heart disease $(n=542)$ & $96(34)$ & $62(24)$ & 0.008 \\
\hline Current smoker & $66(23)$ & $58(22)$ & 0.690 \\
\hline BMI $(n=500)$ mean, SD & $27.3 \pm 3.9$ & $27.3 \pm 6.3$ & 0.908 \\
\hline Hypertension $(n=543)$ & $145(52)$ & $140(53)$ & 0.736 \\
\hline High cholesterol $(n=541)$ & $140(50)$ & $113(43)$ & 0.118 \\
\hline Diabetes & $37(13)$ & $56(21)$ & 0.012 \\
\hline$<3 \mathrm{~h}$ activity a week $(\mathrm{n}=528)$ & $117(43)$ & $133(52)$ & 0.059 \\
\hline
\end{tabular}

Results are shown as number (\%) unless stated otherwise.

${ }^{*} p$ Value obtained using two-sample $t$ test with equal variances for continuous variables and Pearson $\chi^{2}$ for binary variables.

tAttender defined as having attended at least one cardiac rehabilitation session. $\mp$ Non-attender defined as attending no cardiac rehabilitation sessions.

AMI, acute myocardial infarction; BMI, body mass index; $C A B G$, coronary artery bypass graft; $\mathrm{PCl}$, percutaneous coronary intervention.

Mortality of non-attenders compared with attenders

HRs (unadjusted and adjusted) for all-cause mortality of CR non-attenders and attenders are shown in table 3. Non-attenders had a mortality risk that was more than twice that of programme attenders $(\mathrm{p}<0.001)$. This association was attenuated slightly after adjusting for age and sex (model 2), but remained significant $(p=0.001)$. After further adjustment for diagnosis, employment status, diabetes and family history (model 3), the mortality risk for non-attenders was 58\% greater than that of attenders $(\mathrm{p}=0.004)$.

Differences in diabetes status and age were noted in baseline characteristics between non-attenders and attenders that might have accounted for some of the difference seen in mortality. We repeated the analyses excluding patients who reported having diabetes at baseline, finding similar patterns (HR for all-cause mortality $=1.69(95 \%$ CI 1.20 to $2.39, p=0.003)$ adjusted for age, gender, diagnosis employment status, family history). Analysis was repeated excluding participants aged $>70$, again finding similar results (HR for all-cause mortality $=1.65(95 \%$ CI 1.04 to $2.61, p=0.034$ ) adjusted for age, gender, diagnosis, employment status, family history).

\section{Proportion of CR sessions and mortality}

\section{Baseline characteristics}

Few statistically significant trends were seen across the four categories of CR sessions attended (10-24.9\%, 25-49.9\%,
Table 2 Crude all-cause death rates per 10000 person-years for attenders and non-attenders at a cardiac rehabilitation programme; overall and by subgroups

\begin{tabular}{|c|c|c|c|c|}
\hline & \multicolumn{2}{|c|}{ Attenders* } & \multicolumn{2}{|c|}{ Non-attenderst } \\
\hline & $\begin{array}{l}\text { No of } \\
\text { deaths } \ddagger\end{array}$ & $\begin{array}{l}\text { Death rate per } \\
10000 \text { person-years } \\
(95 \% \mathrm{Cl}) \S\end{array}$ & $\begin{array}{l}\text { No of } \\
\text { deaths } ¥\end{array}$ & $\begin{array}{l}\text { Death rate per } \\
10000 \text { person-years } \\
(95 \% \mathrm{Cl}) \S\end{array}$ \\
\hline $\begin{array}{l}\text { Total } \\
(n=544)\end{array}$ & 76 & 210 (168 to 263) & 123 & 429 (359 to 512$)$ \\
\hline $\begin{array}{l}\text { Men } \\
(n=397)\end{array}$ & 54 & 193 (148 to 252) & 78 & 373 (299 to 465$)$ \\
\hline $\begin{array}{l}\text { Women } \\
(n=145)\end{array}$ & 22 & 270 (178 to 411$)$ & 45 & 579 (433 to 776$)$ \\
\hline \multicolumn{5}{|c|}{ Baseline age in years } \\
\hline $\begin{array}{r}\leq 49 \\
(n=83)\end{array}$ & 5 & 76 (32 to 182 ) & 4 & 84 (32 to 225 ) \\
\hline $\begin{array}{c}50-59 \\
(n=129)\end{array}$ & 8 & 84 (42 to 168$)$ & 10 & 127 (68 to 236) \\
\hline $\begin{array}{c}60-69 \\
(n=170)\end{array}$ & 29 & 208 (145 to 300$)$ & 29 & 388 (269 to 558$)$ \\
\hline $\begin{array}{c}\geq 70 \\
(n=160)\end{array}$ & 34 & 558 (399 to 781) & 80 & 930 (747 to 1158 ) \\
\hline $\begin{array}{l}\text { CABG } \\
(n=155)\end{array}$ & 25 & 182 (123 to 270$)$ & 24 & 410 (275 to 611$)$ \\
\hline $\begin{array}{l}\text { AMI } \\
(n=295)\end{array}$ & 44 & 225 (168 to 303$)$ & 75 & 523 (417 to 655$)$ \\
\hline $\mathrm{PCl}(n=92)$ & 7 & 242 (115 to 507$)$ & 24 & 283 (190 to 422$)$ \\
\hline \multicolumn{5}{|c|}{$\begin{array}{l}\text { *Attender defined as attending at least one cardiac rehabilitation session. } \\
\text { †Non-attender defined as attending no cardiac rehabilitation sessions. } \\
\text { ‡Number of fatal events. } \\
\text { §Crude all-cause mortality per } 10000 \text { person-years }(95 \% \mathrm{Cl}) \text {. } \\
\text { AMI, acute myocardial infarction; CABG, coronary artery bypass graft; PCI, } \\
\text { percutaneous coronary intervention. }\end{array}$} \\
\hline
\end{tabular}

50-74.9\%, 75-100\%) except for current smokers (data not shown). Low attenders were more likely to be current smokers $(40 \%, \mathrm{n}=12)$ than were high attenders $(18 \%, \mathrm{n}=33 ; \mathrm{p}$ value for trend across categories $=0.001$ )

Association between proportion of CR sessions attended and mortality

Participants who attended $<25 \%$ of available sessions had an age- and sex-adjusted mortality risk that was more than twice that of participants attending $\geq 75 \%$ of sessions $(p=0.041)$ (table 4). This association was attenuated after adjusting for current smoking $(p=0.133)$. There were no statistically

Table 3 Comparison of hazard ratios for all-cause mortality among non-attenders and attenders at cardiac rehabilitation $(n=542)^{*}$

\begin{tabular}{|c|c|c|c|}
\hline & $\begin{array}{l}\text { Attenderst } \\
\text { Reference }\end{array}$ & $\begin{array}{l}\text { Non-attendersł } \\
\text { HR }(95 \% \mathrm{CI})\end{array}$ & $\begin{array}{l}\mathrm{p} \\
\text { Value }\end{array}$ \\
\hline Model 1: Unadjusted & 1.00 & 2.07 (1.55 to 2.75$)$ & $<0.001$ \\
\hline $\begin{array}{l}\text { Model 2: Adjusted for age and } \\
\text { sex }\end{array}$ & 1.00 & 1.66 (1.24 to 2.23$)$ & 0.001 \\
\hline $\begin{array}{l}\text { Model 3: Adjusted for age, sex, } \\
\text { diagnosis, employment status, } \\
\text { diabetes, family history }\end{array}$ & 1.00 & 1.58 (1.16 to 2.15$)$ & 0.004 \\
\hline
\end{tabular}


Table 4 Association between percentage of cardiac rehabilitation sessions attended and all-cause mortality among programme attenders

\begin{tabular}{|c|c|c|c|c|}
\hline & \multicolumn{4}{|c|}{ Percentage of sessions attended } \\
\hline & $\begin{array}{l}\text { Attended } 10-24.9 \% \\
\text { sessions }(n=30)\end{array}$ & $\begin{array}{l}\text { Attended } 25-49.9 \% \\
\text { sessions }(n=35)\end{array}$ & $\begin{array}{l}\text { Attended } 50-74.9 \% \\
\text { sessions }(n=29)\end{array}$ & $\begin{array}{l}\text { Attended } 75-100 \% \\
\text { sessions }(n=187)\end{array}$ \\
\hline & OR $(95 \% \mathrm{CI})$ & OR $(95 \% \mathrm{CI})$ & & Reference \\
\hline Model 1: Unadjusted & $2.35(1.06$ to 5.19$) p=0.036$ & $1.60(0.74$ to 3.47$) p=0.234$ & $0.64(0.23$ to 1.77$) p=0.389$ & 1.00 \\
\hline Model 2: Adjusted for age and sex & $2.57(1.04$ to 6.38$) p=0.041$ & $1.63(0.69$ to 3.86$) p=0.270$ & $0.91(0.29$ to 2.86$) \mathrm{p}=0.871$ & 1.00 \\
\hline Model 3: Adjusted for age, sex and current smoking & $2.06(0.80$ to 5.29$) p=0.133$ & $1.40(0.58$ to 3.36$) p=0.449$ & $0.78(0.23$ to 2.57$) p=0.676$ & 1.00 \\
\hline
\end{tabular}

significant differences between those attending the two middle categories of sessions and those attending $\geq 75 \%$ of sessions. Across categories of attendance, there appears to be a doseresponse relationship, whereby the lower the proportion of sessions that were attended, the greater the mortality risk, with the exception of the $50-74 \%$ attendance category.

\section{DISCUSSION}

The main findings from this study were that after a 14-year follow-up period, CR non-attenders had a higher all-cause mortality risk than did CR attenders, even after adjusting for baseline differences between groups. We also found a significant ageand sex-adjusted dose-response relationship between the proportion of sessions attended and all-cause mortality. This association became non-significant after further adjustment for baseline differences in smoking status.

\section{Overall benefits of CR}

The findings of this study are consistent with many meta-analyses and systematic reviews reporting significant reductions in all-cause mortality following attendance at comprehensive CR in patients with AMI. ${ }^{1-4}$ The magnitude of the reduction in our study was higher than that seen in these reviews, which generally found a reduction in all-cause mortality of between $20 \%$ and $32 \%$ for CR attenders. These meta-analyses and systematic reviews were predominantly based on smaller trials (dating from the 1970s) and were confined to younger men after AMI, thus excluding women, older patients and other diagnostic groups that are more reflective of the contemporary target group for CR. More recent studies, which have tended to include these patient subgroups, ${ }^{5-8}$ describe an effect from CR of around 50\% reduction in all-cause mortality, more consistent with the $58 \%$ reduction reported by us. For example, a Canadian matched cohort study using registry-based data found a 50\% lower mortality rate at 5 years after CR attendance, ${ }^{5}$ while a study of 2396 PCI patients found a $47 \%$ reduction in all-cause mortality at 12 months in attenders compared with non-attenders. ${ }^{6} 8$

Not all contemporary studies have demonstrated a beneficial effect of CR, however. Two systematic reviews of CR attendance and all-cause mortality found no significant association in subgroup analyses of studies published after $1995,,^{2} 3$ although in both subanalyses the number of included studies was low, the 95\% CI boundaries crossed (reducing significance of results) and populations were limited to younger male patients with AMI. The recent Rehabilitation After Myocardial Infarction Trial (RAMIT) from the UK found no effect of CR attendance on all-cause mortality, ${ }^{19}$ although the study methodology has been criticised. ${ }^{20-22}$ Findings from RAMIT have led to suggestions that comprehensive CR may no longer be relevant in view of routinely used and highly effective treatments such as $\beta$ blockers, statins and early revascularisation. ${ }^{19}$ However, others suggest that the RAMIT findings demonstrate not that CR itself is ineffective, but that CR as performed in the late 1990s in the UK was not 'fit for purpose'. ${ }^{20} 23$ The UK model of CR is very similar to the Australian model described in our study. Although recent recommendations for $\mathrm{CR}$ in both countries encourage a more comprehensive approach, ${ }^{23} 24$ problems of funding, staffing, referral and attendance rates remain, ${ }^{20}$ all of which will continue to affect the optimal delivery of CR.

A further question remains about the continuing need for $\mathrm{CR}$, given the population-level decline in CHD mortality over the past few decades. There is recent evidence that this decline is slowing among people aged $<55$ years. ${ }^{25} 26$ This pattern may be due to an increasing prevalence of diabetes and obesity in this age group ${ }^{25}$ both of which are major risk factors for CHD. ${ }^{27}$ UK studies exploring the changing clinical profile of CR attenders between the 1990s and 2006 found that while there was a very large increase in statin use and a subsequent improvement in lipid parameters, participants were now more commonly diagnosed with diabetes and were more likely to be obese. $^{28} 29$ This trend suggests that there will be a continuing need for interventions such as CR.

\section{Long-term benefits of CR}

The long-term association between $\mathrm{CR}$ attendance and mortality has been studied rarely. ${ }^{9-11}$ A randomised controlled trial of 651 men with AMI attending an exercise-only programme in the USA found no difference in all-cause or cardiac mortality at 19 years. ${ }^{10}$ Conversely, a Swedish observational study of 305 men and women after AMI found that attendance at CR was associated with a reduction in all-cause mortality (37\% vs $48 \%$ ) after 10 years, but not after 5 years. ${ }^{9}$ These were earlier studies (with the majority of patients enrolled in the 1970s) and outcomes might have been influenced by the changes in medical management that occurred during the 1980s and early 1990s, such as the introduction of $\beta$ blockers in 1985 and of ACE inhibitors and statins in $1994-5 .^{19}$ No contemporary studies have investigated the effects of CR on mortality in patients with combined AMI, CABG and PCI over a period of 10 years or more. Ours is the first study to do so and indicates that CR may have a sustained benefit on mortality.

Although the short-term benefits of $\mathrm{CR}$ on risk factors are clear (with risk factor reductions accounting for about half of the mortality reduction associated with CR), ${ }^{30}$ less research has been undertaken on the long-term impact of behavioural changes that begin in CR. CHD progresses over many years, ${ }^{2}$ and therefore long-term follow-up of patients with $\mathrm{CHD}$ will provide valuable evidence for strategies that may be effective in slowing progression of the disease. Findings such as ours lend support to the sustainability of the beneficial effects of CR, 
although further research is required into the mechanisms by which this benefit occurs.

\section{Dose-response and CR}

It is unclear as to whether attending a greater proportion of CR sessions offers a greater benefit to patients ('dose-response relationship'). A systematic review and meta-analysis of 48 randomised controlled trials $(n=8940$ patients) found no doseresponse, ${ }^{2}$ while two recent registry-based studies $^{7}{ }^{8}$ of Medicare beneficiaries aged $>65$ years found that attending a higher number of CR sessions was associated with a significant reduction in mortality of between $19 \%$ and $47 \%$. It is important to note that in these studies, 'dose' was modelled as a binary variable possibly reducing its sensitivity, whereas our analysis modelled 'dose' in four groups. Furthermore, in Australia, the majority of CR programmes offer low-to-moderate exercise intensity only and programme duration is generally between six and 12 sessions. This format differs from the CR programmes in the above studies (in which programme duration is as long as 36 sessions), making comparison with our study difficult. Nevertheless, our findings add support to the suggestion that attending a higher proportion of CR sessions confers greater long-term benefit than attending fewer sessions.

Our findings also showed that while a dose-response relationship may exist between the proportion of sessions attended and long-term mortality, this does not occur independently of smoking differences. When our analyses were adjusted for the fact that low attenders are more likely to be smokers, the doseresponse relationship became non-significant, indicating that smoking may account for the mortality differences. This is not surprising given the important relationship between smoking and mortality, in which smoking has been shown to account for $35 \%$ of the risk of AMI. ${ }^{27}$ In this sample, current smoking is not a 'confounder' of the association between mortality and the proportion of sessions attended because smoking status was not independently associated with mortality. However, given there was a baseline difference in smoking prevalence between low and high attenders and given the established relationship between smoking and increased risk of death, it was considered important to adjust for this variable in analyses. The lack of association between current smoking and mortality may be due to a number of factors, including the cause of death not being smoking related for most participants, incorrect self-report of smoking, or a reduction in smoking prevalence among patients after their cardiac event. Thus, the results should be interpreted with caution.

As previously reported, ${ }^{12}$ smoking is a predictor of discontinuing CR and it may be that smokers feel isolated and stigmatised during programme attendance. CR practitioners must ensure that strategies are in place to encourage smokers to complete CR sessions by, for example, providing extra support and referral to smoking cessation services where required.

\section{Strengths and limitations of the study}

Our study has several strengths. By studying the mortality effect of CR attendance over a 14 year period, we were able to produce evidence suggestive of the long-term sustainability of patient benefits achieved through CR. Most previous studies have only tracked mortality status of patients for 6 months to 5 years after their acute cardiac event. Our study is also contemporary and includes patients consecutively admitted into a public hospital, thus providing a representative sample of cardiac patients in Australian metropolitan hospitals. Our patient sample included three different groups-namely, patients with AMI, PCI and CABG. This heterogeneity allows for a broader understanding of how CR independently predicts mortality after a range of coronary events.

Finally, in most previous observational studies, CR programme attendance was limited to those patients who were formally referred by their physicians. In this study, however, hospitals from which these patients were recruited practised a policy of routine CR referral. Hence, attendance patterns were investigated in a sample that was presumably not affected by physician selection bias. A recent review of CR referral methods ${ }^{31}$ found that automatic referral increased referral rates, with this strategy recommended for all inpatient units in order to increase CR enrolment and participation. ${ }^{14}$

There were some limitations to this study. We were unable to adjust for all known covariates. For example, the baseline study from which this project was derived did not investigate psychosocial factors known to influence CR attendance or long-term health outcomes, including patient beliefs and perceptions and the presence of symptoms of anxiety and depression. In addition, most clinical characteristics reported were based on patient self-report with no external validation. Further, the original attendance patterns study was not designed to assess longterm mortality outcomes and there might have been insufficient power to detect a true association between CR attendance and mortality. Although our study did include women and a range of age groups, the sample predominantly comprised men $(73 \%)$ of younger age (mean age $62.5 \pm 11.3$ years). Additionally, it is acknowledged that changes might have occurred to CR programme delivery, although the model of $\mathrm{CR}$ practised in Australia has changed little since the late 1990s. Finally, no information about the severity of the cardiac event was obtained and controlled for in analysis, although we did exclude patients who died within 12 months of their cardiac admission date, thus reducing the risk of survivor bias. ${ }^{5} 13$

\section{Further research}

Evidence for the benefits of comprehensive CR programmes is strong and research should now focus on the 'gaps'. These include the development of interventions to encourage referral to, and participation in, CR and the testing of strategies to enhance patient retention, particularly among those population groups who do not attend CR such as smokers, women and younger patients. Investigators should also continue to produce evidence for alternative models of cardiac secondary prevention so that patients can choose from a range of options.

Observational studies need to be undertaken using larger samples from a variety of populations and countries. Such studies might identify predictors of 'successful' CR programmes and would also allow for subgroup analysis; for example, stratification of outcomes by socioeconomic status to assess the potential impact of CR on health inequalities. Collection of appropriate baseline data would also allow for exploration of the mechanisms by which CR confers long-term benefit.

\section{CONCLUSION}

Findings from this study provide further support for the longterm benefits of CR in a contemporary, heterogeneous population. We should continue to recognise that comprehensive models of CR have significant benefits for healthcare. Given the projected increase in obesity, diabetes and hence CHD, the need for effective interventions such as CR that are shown to reduce CHD mortality remains. 
Acknowledgements We thank Dr Michelle Macvean and Ms Jan Kleiman for their assistance with data collection.

Contributors $A B$ contributed to data preparation and analysis, interpretation of results and manuscript preparation and accepts overall responsibility for the publication. MW, JT, LG, RN and AG contributed to the design and conduct of the original study and manuscript preparation. AN and BM assisted with data preparation, interpretation of results and manuscript preparation.

Funding The original attendance patterns study was supported by a 3-year grant from the Australian Commonwealth Department of Health and Ageing.

\section{Competing interests None.}

Ethics approval Australian Institute of Health and Welfare; Melbourne Health.

Provenance and peer review Not commissioned; externally peer reviewed.

\section{REFERENCES}

1 Oldridge NB, Guyatt GH, Fischer ME, et al. Cardiac rehabilitation after myocardial infarction. JAMA 1988;260:945-50.

2 Taylor RS, Brown A, Ebrahim S, et al. Exercise-based rehabilitation for patients with coronary heart disease: systematic review and meta-analysis of randomized controlled trials. Am J Med 2004;116:682-92.

3 Lawler PR, Filion KB, Eisenberg MJ. Efficacy of exercise-based cardiac rehabilitation post-myocardial infarction: a systematic review and meta-analysis of randomized controlled trials. Am Heart J 2011:162:571-84.e2.

4 Heran BS, Chen JMH, Ebrahim S, et al. Exercise-based cardiac rehabilitation for coronary heart disease (Review). The Cochrane Libr 2011(8).

5 Alter DA, Oh PI, Chong A. Relationship between cardiac rehabilitation and survival after acute cardiac hospitalization within a universal health care system. Eur J Cardiovasc Prev Rehabil 2009:16:102-13.

6 Goel K, Lennon RJ, Tilbury RT, et al. Impact of cardiac rehabilitation on mortality and cardiovascular events after percutaneous coronary intervention in the community. Circulation 2011;123:2344-52.

7 Hammill BG, Curtis LH, Schulman KA, et al. Relationship between cardiac rehabilitation and long-term risks of death and myocardial infarction among elderly medicare beneficiaries. Circulation 2010;121:63-70.

8 Suaya JA, Stason WB, Ades PA, et al. Cardiac Rehabilitation and Survival in Older Coronary Patients. J Am Coll Cardiol 2009;54:25-33.

9 Hedbäck B, Perk J, Wodlin PLong-term reduction of cardiac mortality after myocardial infarction: 10-year results of a comprehensive rehabilitation programme. Eur Heart J 1993:14:831-5.

10 Dorn J, Naughton J, Imamura D, et al. Results of a multicenter randomized clinical trial of exercise and long-term survival in myocardial infarction patients. J Cardiopulm Rehabil Prev 2000;20:130.

11 Hämäläinen $\mathrm{H}$, Luurila $\mathrm{O}$, Kallio $\mathrm{V}$, et al. Reduction in sudden deaths and coronary mortality in myocardial infarction patients after rehabilitation. Eur Heart J 1995;16:1839-44.

12 Worcester M, Murphy B, Mee V, et al. Cardiac rehabilitation programmes: predictors of non-attendance and drop-out. Eur J Cardiovasc Prev Rehabil 2004;11:328-35.

13 Martin B-J, Hauer T, Arena R, et al. Cardiac rehabilitation attendance and outcomes in coronary artery disease patients/clinical perspective. Circulation 2012;126:677-87.
14 Goble A, Worcester M. Best practice guidelines for cardiac rehabilitation and secondary prevention. Victoria: Melbourne Heart Research Centre (on behalf of Department of Human Services, Victoria), 1999.

15 Lane $\mathrm{D}$, Carroll D, Ring $C$, et al. Predictors of attendance at cardiac rehabilitation after myocardial infarction. J Psychosom Res 2001:51:497-501.

16 Australian Bureau of Statistics. http://www.abs.gov.au/ (cited 2012 May) (accessed September 8th 2012).

17 Risk Factor Prevalence Study Management Committee. Risk factor prevalence study, survey no. 3, 1989. Canberra: National Heart Foundation of Australia and Australian Institute of Health, 1990

18 Magliano D, Liew D, Pater H, et al. Accuracy of the Australian National Death Index: comparison with adjudicated fatal outcomes among Australian participants in the Long-term Intervention with Pravastatin in Ischaemic Disease (LIPID) study. Aust N ZJ Public Health 2003:27:649-53.

19 West RR, Jones DA, Henderson AH. Rehabilitation after myocardial infarction trial (RAMIT): multi-centre randomised controlled trial of comprehensive cardiac rehabilitation in patients following acute myocardial infarction. Heart 2011;98:637-44

20 Doherty $\mathrm{P}$, Lewin R. The RAMIT trial, a pragmatic RCT of cardiac rehabilitation versus usual care: what does it tell us? Heart 2012;98:605-6.

21 Taylor RS. The RAMIT trial: its results in the context of 2012 Cochrane review. Heart 2012;98:672-3.

22 BACPR Elected Council Members. RAMIT presents an outdated version of cardiac rehabilitation. Heart 2012;98:672.

23 Wood D. Is cardiac rehabilitation fit for purpose in the NHS: maybe not. Heart 2012:98:607-8

24 National Heart Foundation, Australian Cardiac Rehabilitation Association. Recommended framework for cardiac rehabilitation '04. National Heart Foundation, Canberra, Australia, 2004.

25 Ford ES, Capewell S. Coronary heart fisease mortality among young adults in the $\mathrm{U}$. S. from 1980 through 2002: concealed leveling of mortality rates. J Am Coll Cardiol 2007:50:2128-32.

26 O'Flaherty M, Ford E, Allender S, et al. Coronary heart disease trends in England and Wales from 1984 to 2004: concealed levelling of mortality rates among young adults. Heart 2008;94:178-81.

27 Yusuf S, Hawken S, Ôunpuu S, et al. Effect of potentially modifiable risk factors associated with myocardial infarction in 52 countries (the INTERHEART study): case-control study. Lancet 2004;364:937-52.

28 Audelin M, Savage P, Ades PA. Changing clinical profile of patients entering cardiac rehabilitation/secondary prevention programs: 1996 to 2006. J Cardiopulm Rehabil Prev 2008;28:299-306.

29 Evans J, Bethell H, Turner S, et al. Characteristics of patients entering cardiac rehabilitation in the United Kingdom 1993-2006: implications for the future. J Cardiopulm Rehabil Prev 2011;31:181-7.

30 Taylor RA, Dobson AA, Mirzaei MB. Contribution of changes in risk factors to the decline of coronary heart disease mortality in Australia over three decades. Eur $J$ Cardiovasc Prev Rehabil 2006;13:760-8.

31 Gravely-Witte S, Leung Y, Nariani R, et al. Effects of cardiac rehabilitation referral strategies on referral and enrollment rates. Nat Rev Cardiol 2010;7: 87-96. 